\title{
Implications upon using exterior post-tensioning tendons to retrofit a low strength concrete waffle slab
}

\author{
Andrei Faur $^{1, *}$, Virág Jacint ${ }^{1}$ \\ ${ }^{1}$ Department of Structures, Faculty of Civil Engineering, TUCN, 25, G. Barițiu Street, 400027, Cluj-Napoca, Romania
}

\begin{abstract}
A common problem when casting reinforced concrete structures is to have a lower concrete compressive strength as opposed to what has been assumed in design. The deflections that may occur under the serviceability conditions can exceed the maximum allowed. Although less frequent nowadays, there is still an ongoing demand to offer simple and practical retrofitting solutions for such situations. To cast a new concrete layer above an existing waffle slab facing these problems is sometimes, only by appearance, the simplest retrofitting method. The major disadvantages reside in the growth of the overall steel consumption and overall weight of the structure. Additional reinforcement is needed for the new slab and at the interface of the two concretes. Interventions that are not always simple and accessible to the builder may still be needed to satisfy the strength demands of the already cast elements. Therefore, a post-tensioning system placed bellow the existing concrete seems to be a better solution. The present study refers to a real-case investigation on a 5-level residual building where a low concrete class was identified for several waffle slabs. Casting an overall top concrete slab or applying an exterior post-tensioning system were the two main retrofitting solutions offered by the designer. Both solutions are compared in terms of structural performance and cost efficiency.
\end{abstract}

\section{Introduction}

The present paper refers to a real-case investigation upon finding the proper solution for retrofitting several waffleslabs. The problem appeared at the construction site, where lower concrete strengths were obtained after casting the first slabs. Concerns coming from the builder about the whole structure being compromised started to emerge. This was mainly because at the time this problem was identified, the first three floors were already built. Therefore, a third-party designer offered the expertise to inspect the current situation and to propose a retrofitting solution if necessary.

The preliminary inspection revealed that the concrete did not achieve the prescribed strength at the time the insitu core samples were tested. All the collected concrete cores had a diameter of 60 to $65 \mathrm{~mm}$ and a length to diameter ratio of approximately 1 (i.e. 3 to 4 samples having 60 to $65 \mathrm{~mm}$ in diameter and length were collected from each structural element). The cores were tested under laboratory conditions after 8 days, and the procedures from NP 137:2014 [1] and EN 13791:2007 [2] were used to determine the in-situ characteristic concrete strength.

The concrete strength loss was detected not only for slabs, where the concrete reached as far as the equivalent of two concrete classes below the design prescription, but in all the concrete elements. By the time the first retrofitting solutions were proposed, a new batch of insitu cores were tested, revealing a slight raise of the compression strength. This was assumed to be caused by the ongoing curing process, mainly because the time difference between the two measurements was approximately one month, and the weather was favourable during this time (i.e. relatively high temperatures combined with normal humidity levels). Anyway, it was concluded that only the already cast waffle-slabs needed to be retrofitted, and this to fulfil the serviceability requirements. The retrofitting solutions are discussed in the following.

\subsection{A brief description of the building}

The building in discussion is conceived mainly as residential and combined with a few office areas and parking lots at the basement floor. The structural system consists of reinforced concrete waffle-slabs supported by perimeter walls, beams and columns. The building has six openings along the longitudinal direction and a single opening along the transversal direction. It has a total of six storeys with unsymmetrical setbacks along the longitudinal direction, the first three floors being cast at the time the investigation started. The distance between the transversal axes is of 12 meters, while the distances between the longitudinal axes vary between 2.8 and 8 meters. Therefore, there are two regions for each floor where the waffle-slab has an area of $8 \times 12$ meters (i.e. 96 $\mathrm{m}^{2}$ ) between the axes, and consequently between the support elements. A 3-D representation of the structural system is presented in Fig. 1, and the first-floor layout in Fig. 2.

\footnotetext{
* Corresponding author: andrei.faur @ dst.utcluj.ro
} 


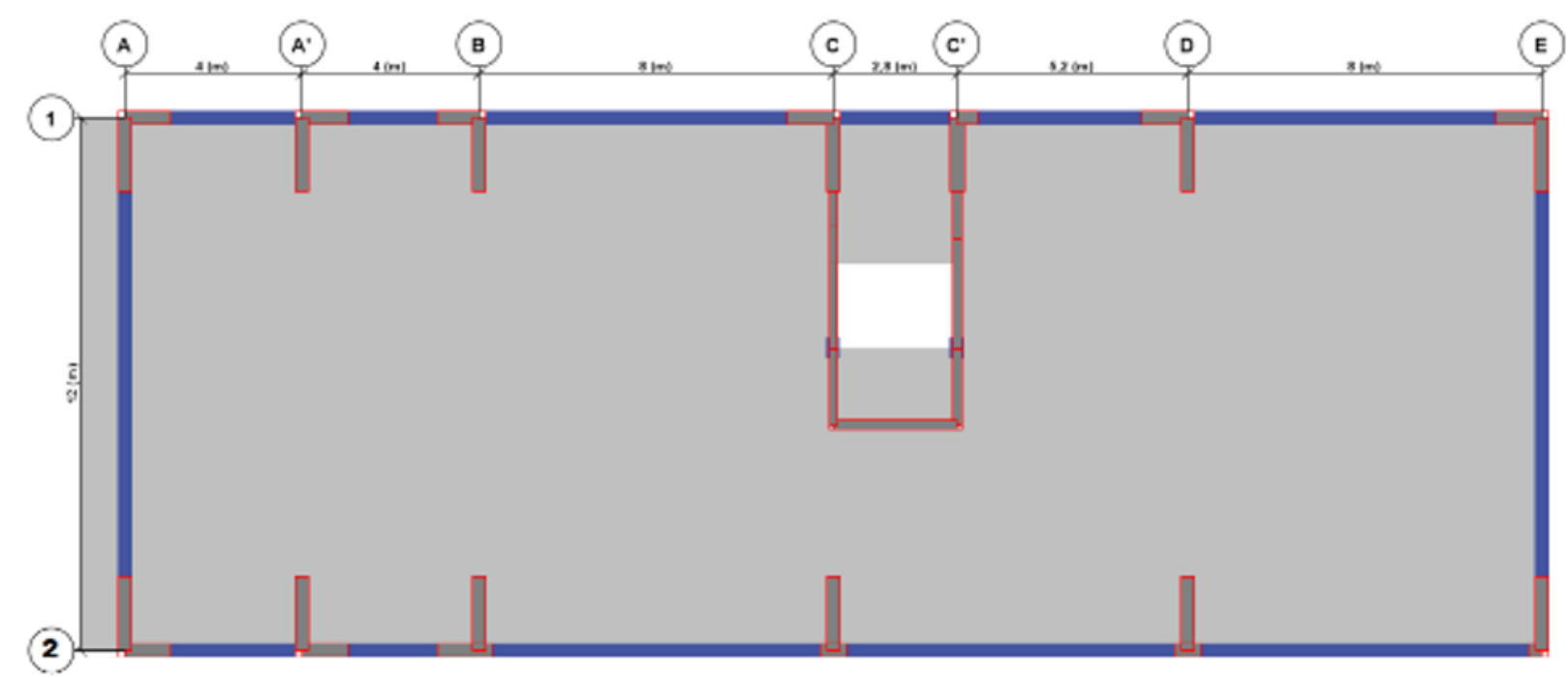

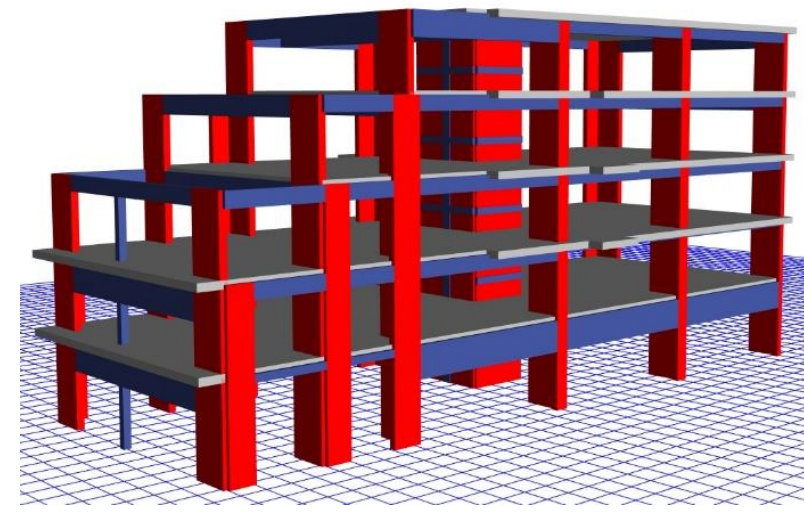

Fig. 1. First floor layout.

Fig. 2. 3-D representation of the structural system.

The first two floors have no setbacks. At the third floor the slab stops at gridline A', and from here it starts to withdraw at gridline $\mathrm{B}$ and at the middle between gridlines $\mathrm{B}$ and $\mathrm{C}$ for the fourth and the fifth floor, respectively. The edges of the slabs were strengthened with reinforced concrete beams in order to prevent excessive deflections.

The storey height is equal to $3.06 \mathrm{~m}$, except for the basement floor, where the height is $3.73 \mathrm{~m}$.

The building is located in Cluj County, Romania.

\subsection{The structural system}

Based on the building's architecture, the floors were conceived as waffle-slabs, except for the areas near the vertical supports (i.e. walls and columns) and along the strips following the axes A', B, C and D. No supporting ribs were used in these areas, but $30 \mathrm{~cm}$ thick solid slabs were cast instead. The overall depth of the waffle-slab is also $30 \mathrm{~cm}$.

The reinforced concrete walls are arranged as vertical piers of $30 \mathrm{~cm}$ thickness. These are depicted in Fig. 2 with red colour. Rectangular section beams or confinement beams are placed on the perimeter to sustain the slab edges and are depicted in the same Fig. 2 with blue colour. The structure for the staircase is made of frame elements (i.e. columns and beams) and filled with masonry panels.
The ramps and the pedestals are designed as $18 \mathrm{~cm}$ reinforced concrete flat slabs.

The concrete class assumed in design is C16/20 and the steel for the reinforcement has a yield strength of 345 $\mathrm{kPa}$ and a tensile strength of $510 \mathrm{kPa}$.

\section{Preliminary tests and structural expertise}

At the time the structure was built up to the third floor (i.e. the foundations, the ground floor, the semi-basement floor and the ground floor's top slab) it was found that the concrete in some elements had a lower compression strength than that established by design. The cause of this problem is still under investigation. It was revealed based on the in-situ and laboratory tests that almost all the structural elements were affected. The compression strength of the in-situ cubic concrete samples and their equivalent concrete class are summarised in Table 1:

Table 1. In-situ samples test results.

\begin{tabular}{|c|c|c|}
\hline Structural element & $\begin{array}{c}f_{c k, c u b e}^{i s} \\
{[\mathrm{MPa}]}\end{array}$ & Equivalent concrete class \\
\hline Basement Walls & 16.19 & $\mathrm{C} 16 / 20$ \\
\hline $\begin{array}{c}\text { Basement Top } \\
\text { Slab }\end{array}$ & 10.43 & $\mathrm{C} 8 / 10$ to $\mathrm{C} 12 / 15$ \\
\hline $\begin{array}{c}\text { Semi-basement } \\
\text { Walls }\end{array}$ & 9.91 & $\mathrm{C} 8 / 10$ \\
\hline $\begin{array}{c}\text { Semi-basement } \\
\text { Top Slab }\end{array}$ & 11.73 & $\mathrm{C} 8 / 10$ to $\mathrm{C} 12 / 15$ \\
\hline $\begin{array}{c}\text { Ground Floor } \\
\text { Walls }\end{array}$ & 13.82 & $\mathrm{C} 12 / 15$ \\
\hline $\begin{array}{c}\text { Ground Floor Top } \\
\text { Slab }\end{array}$ & $\approx 10$ & $\mathrm{C} 8 / 10$ \\
\hline
\end{tabular}

where $f_{c k, \text { cube }}^{i s}$ is the concrete characteristic cube strength of the in-situ samples. All the mentioned values were determined accordingly with the Romanian standard for the assessment of in-situ compressive strength in concrete 
structures NP 137:2014 [1], and the European standards Eurocode 2 [3] and EN 13791:2007 [2].The structural technical expertise was performed based on these tests. The capacity of the structural system having the new concrete properties was established by running several numerical analyses. The computations were done through the use of ETABS [4] analysis program. Both the vertical and the horizontal (i.e. the territory of Romania is fully regarded as an active seismic region) types of analyses were performed for both the ultimate and the serviceability limit states. The results revealed the necessity to retrofit the waffle-slabs and two solutions were proposed to the builder as being the most efficient:

- by pouring a new a new concrete layer over the existing slabs, or

- by placing a post-tensioning system below the existing slabs.

Both retrofitting solutions were proposed because the analyses showed excessive vertical deflections of the slabs in the large spanning areas (i.e. between axes B-C and D-E). The maximum allowed deflections for the serviceability state were supposed to be exceeded by far in the future if no structural interventions are made immediately to the slabs. Moreover, the shear and the flexural forces developed in some slab ribs exceeded the ultimate limit state conditions under the new concrete strength values. Therefore, not only the stiffness but also the strength of the waffle-slabs has to be increased as quickly as possible. Both retrofitting solutions are discussed in the following. The builder excluded the demolition starting from the basement top slab, even if a C8/10 class concrete is not suitable for constructional purposes, claiming he was behind works.

\section{Numerical analyses}

All the numerical models were developed in ETABS [4] and SAP2000 [5]. Several 3-D models representing the complete structure were preferred against simpler 2-D representations. These were intended to capture the interaction between different elements to both vertical and lateral loads. Simpler numerical models were still used but only for finding the mechanical characteristics of the waffle slabs.

\subsection{Analysis of the initial state of the slabs}

One of the most delicate parts of the expertise was the evaluation of the waffle-slab mechanical properties. One of the first studies referring to the orthotropic behaviour of the slabs were those of Timoshenko and WoinowskyKrieger [6]. While being mathematically rigorous, the authors of the mentioned publication restrict their theory to simple geometries and boundary conditions. Even so, the shape functions for finding the deflected shape of the shells are too complex to be used in a finite element context. Other authors proposed simpler shape functions [7], and finite element formulation for specific waffle-slab shell elements were developed since the 80's [8].
Therefore, the analytical approach is considered to be too time consuming, while other methods requiring high finite element knowledge are far to impractical.

In order to simplify the analysis, it was decided to model the waffle-slab as a flat slab with similar stiffness and strength properties. The SAP2000 [5] analysis program was used for this purpose. The equivalent thickness of the slab was determined following several trials of comparing the vertical deflections of two numerical models:

- The first model - consisted in a flat slab having the dimensions of $8 \mathrm{~m} \times 12 \mathrm{~m}$ and $205 \mathrm{~mm}$ in thickness;

- The second model - consisted in a real representation of the waffle-slab with $0.75 \mathrm{~m}$ spaced frame elements as ribs $(0.15 \mathrm{~m} \times 0.30 \mathrm{~m}$ are the cross-sectional dimensions) and a $8 \mathrm{~mm}$ top slab, and having the same $8 \mathrm{~m} \times 12 \mathrm{~m}$ dimensions as the first model.

Moreover, the $8 \mathrm{~mm}$ slab used in the second model was placed at the top of the frame elements. Plate-Thin shell elements (i.e. supports only bending moments and transverse forces [5]) were used in both models. The inplane behaviour was neglected for simplifying the computation and for not overestimating the slab's rigidity. Anyway, the infinite diaphragm hypothesis is assumed for all the 3-D models and, therefore, such simplification is justified.

The openings for both models were chosen with respect to the large spanning areas of the slabs (i.e. the regions where the maximum vertical deflections are likely to occur). Pinned supports were placed along the perimeter to simulate the boundary conditions of the real slab. The finite element analyses were performed after the discretisation of the area elements and the same vertical displacement was obtained for a $205 \mathrm{~mm}$ thickness of the flat slab. The difference between the results was under $1 \%$ (i.e. the vertical displacement for the flat slab model was $14.6 \mathrm{~mm}$, and $14.5 \mathrm{~mm}$ for the beam-slab model). The deformed shapes of both models are presented in Fig. 3, where $u_{z}$ represents the vertical displacement. A vertical load of $10 \mathrm{kN} / \mathrm{m}^{2}$ was used for both analyses.
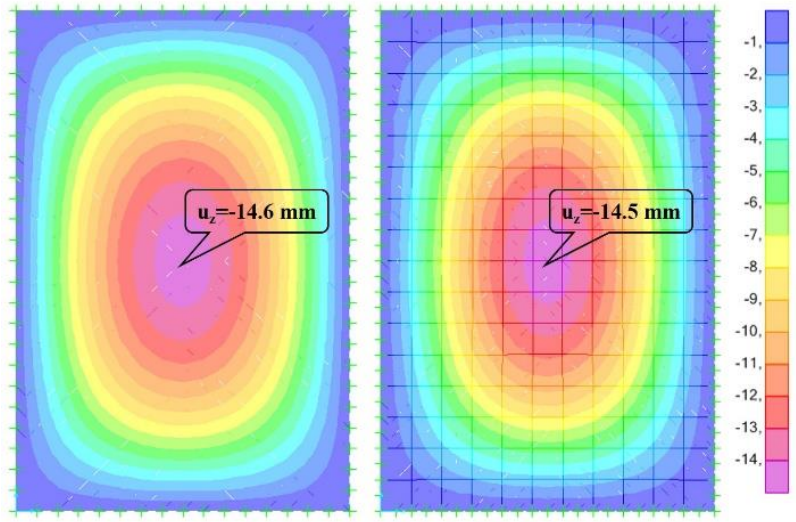

Fig. 3. Vertical displacement of the equivalent flat slab model (left) and the frame-slab model (right). 
Based on the obtained results, it was concluded that similar stiffness properties can be obtained if the slab is modelled with simple area finite elements of $205 \mathrm{~mm}$ in thickness.

It is mandatory that the slab deflections must be verified for the serviceability limit states (SLS) under these new conditions of concrete strength loss. The total deformation including creep may be calculated by using an effective modulus of elasticity for concrete, as indicated in Eurocode 2 [3]:

$$
E_{c, e f f}=\frac{E_{c m}}{1+\varphi\left(\infty, t_{0}\right)}
$$

where: $E_{c, e f f}-$ effective modulus of elasticity of concrete; $E_{c m}$ - secant modulus of elasticity of concrete; and $\varphi(\infty$, $\left.t_{0}\right)$ - final value of creep coefficient. The age of concrete at the time of loading $t_{0}$ was taken as 28 days and 21000 $\mathrm{MPa}$ was considered as the secant modulus of elasticity for the $\mathrm{C} 8 / 10$ concrete class. The secant modulus for each structural element was taken accordingly with the data presented in Table 1. The final values of the creep coefficient for the waffle-slabs were estimated as 2.65 for the $\mathrm{C} 16 / 20$ concrete class, 2.85 for $\mathrm{C} 12 / 15$, and 3.35 for $\mathrm{C} 8 / 10$. Therefore, an approximatively four-time reduction in the total flexural stiffness of the slabs (i.e. the product of the effective modulus of elasticity and the moment of inertia) results for the SLS analysis.

The loads were applied on slabs and on frames. The permanent loads, except the self-weight of the structural elements, were taken as $1.45 \mathrm{kPa}$ and were applied on slabs. The live loads were taken as $2.70 \mathrm{kPa}$ for the residential areas and 3.70 for the office areas but including the self-weight of the movable partitions. Based on these loadings and stiffness properties, the maximum SLS deflections of the slabs at the quasi-permanent combinations are presented in the following figures:

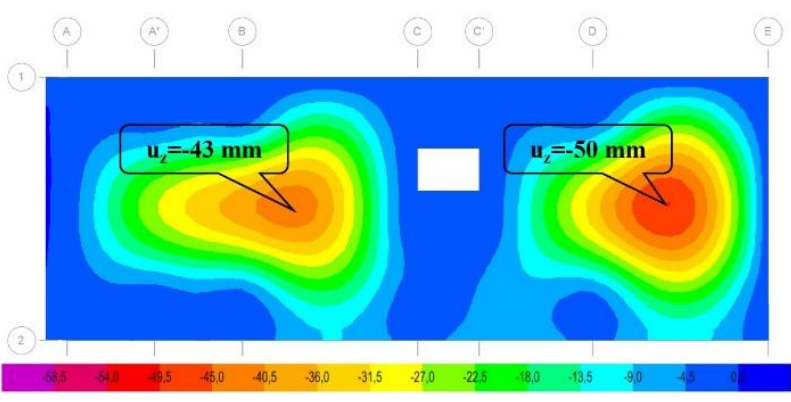

Fig. 4. Slab deformed shape - basement floor.

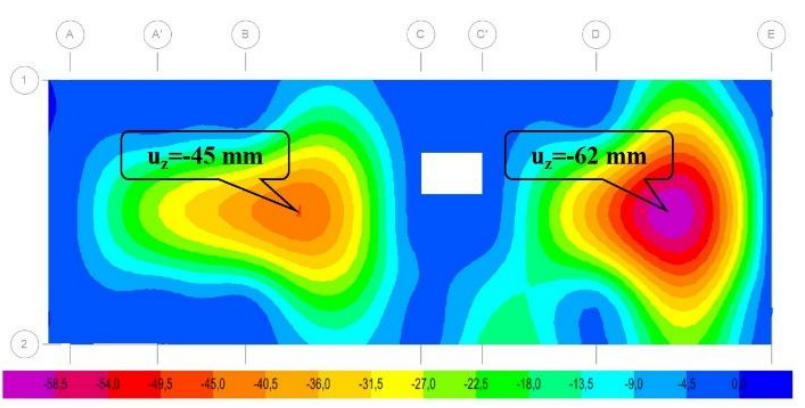

Fig. 5. Slab deformed shape - semi-basement floor.

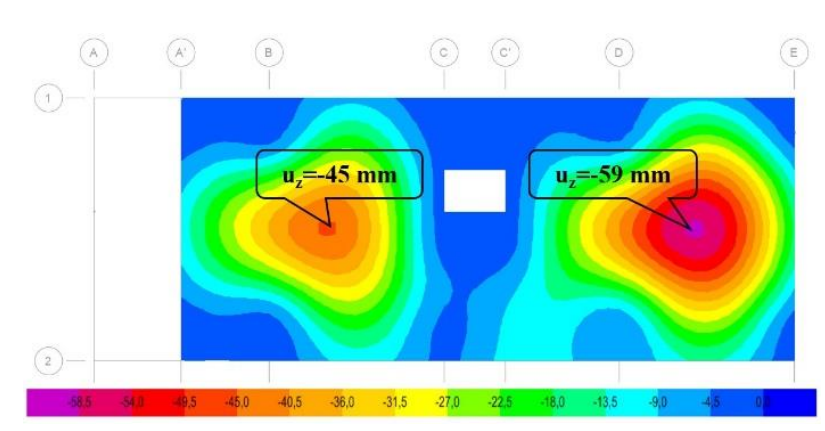

Fig. 6. Slab deformed shape - ground floor.

If the maximum deflection is restricted to span/250 (i.e. for the $8 \mathrm{~m}$ spans between axes B-C and D-E the maximum allowed deflection is $32 \mathrm{~mm}$ ), then the presented deflections exceed this value by far. The slab deflection between axes $\mathrm{D}$ and $\mathrm{E}$ at the basement floor is almost twice higher than the maximum allowed (i.e. $93.78 \%$ higher). Retrofitting of the slabs is mandatory in this situation.

Based on the reinforcement plans and the ultimate limit state (ULS) analysis it was found that the element forces in some regions are greater than the yield forces, but do not exceed the resisting moments, shear forces, or the resisting axial forces. Therefore, no other structural interventions beside the two proposed retrofitting solutions were predicted at this stage.

\subsection{The top concrete layer model}

The simplest solution to overcome the serviceability deflections of the slabs seems to be realized by pouring a concrete layer above the existing waffle-slabs. The rigidity should increase and, therefore, the deflections should drop below the admissible values. Following a series of numerical computations, it was found that the minimum requirements are achieved if the reinforced concrete top layer has at least $60 \mathrm{~mm}$ in thickness and the concrete class is $\mathrm{C} 30 / 37$.

The retrofitted slabs were modelled in ETABS [4] with layered shell elements (i.e. a type of area object composed of multiple overlaid shells, see [4]). As in the previous case, the existing waffle-slab was considered as an equivalent flat slab of $205 \mathrm{~mm}$ in thickness. The supplementary $60 \mathrm{~mm}$ slab of higher concrete class was placed above, and perfect bond was considered between the two concretes. This last assumption will be respected by providing enough reinforcement crossing the interface. The increase in stiffness resulted by over-concreting was estimated as being 2.5 to 3 times higher, depending on the existing concrete strength and the creep.

It should be mentioned that the stiffness has been evaluated based on the same principles that led to the finding of the equivalent thickness of the flat slab: the vertical deflection of the initial and the retrofitted slabs were compared under the same load, boundary and geometry conditions (i.e. $8 \mathrm{~m} \times 12 \mathrm{~m}$ simply supported slabs loaded with a uniformly distributed vertical load of $10 \mathrm{kN} / \mathrm{m})$. 
The maximum SLS deflections of the slabs at the quasi-permanent combinations for the new layered slabs are presented in Fig. 7, Fig. 8 and Fig. 9. It may be observed that the maximum deflections are lower than in the absence of the top concrete layer. The maximum allowed deflection of $32 \mathrm{~mm}$ is nowhere reached (i.e. the highest resulted value of $23 \mathrm{~mm}$ being $28 \%$ lower than the admissible limit). Therefore, the SLS deflection criteria are fulfilled if the existing waffle-slabs are retrofitted with a top reinforced concrete layer of $60 \mathrm{~mm}$ in thickness and C30/37 concrete class.

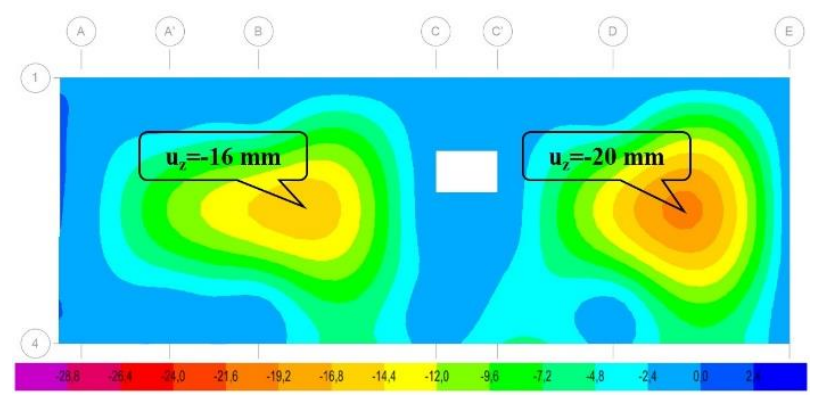

Fig. 7. Over-cast slab deformed shape - basement floor.

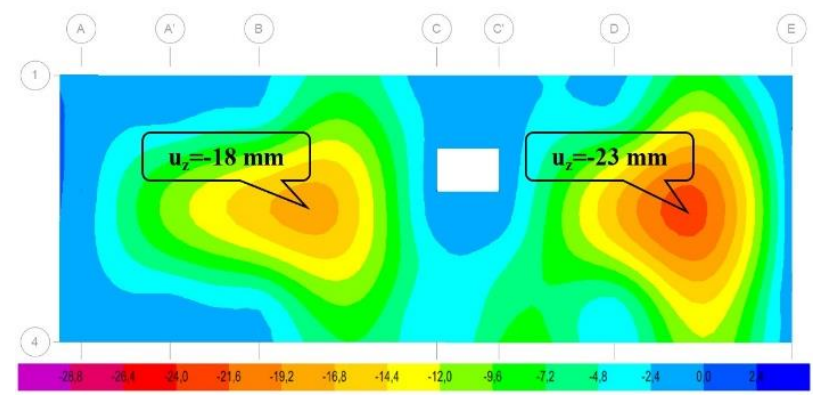

Fig. 8. Over-cast slab deformed shape - semi-basement floor.

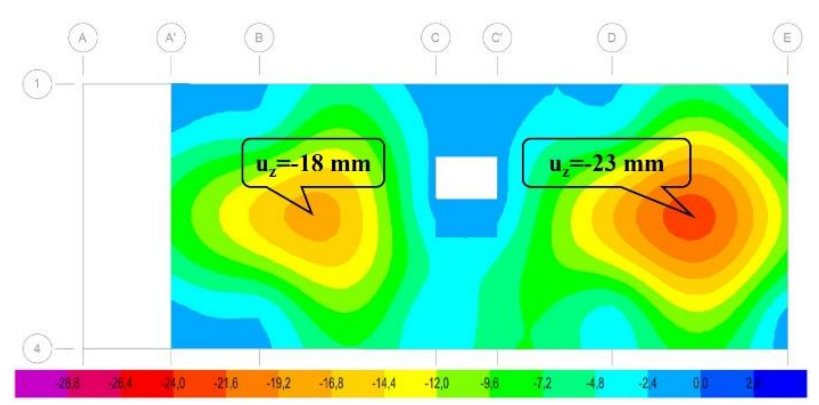

Fig. 9. Over-cast slab deformed shape - ground floor.

One problem with this retrofitting solution was observed during the analysis. It referred to the ultimate limit state (ULS) verifications. Some of the existing slab ribs, especially those located near the edges parallel to axes 1 and 4, were subjected to forces that were higher than these rib elements were capable to overcome. Therefore, the design flexural moments and shear forces cannot be undertaken if no supplementary structural interventions are made.

These forces become almost twice higher than in the absence of the top concrete layer. Such a force redistribution is supposed to be caused by the slab's overall stiffness growth, thus directing the forces towards the supports. While this phenomenon seems to be favourable for low concrete strengths (i.e. causing a force redistribution towards the middle of the slabs where sufficient reinforcement is provided), an initial design error cannot be excluded. Whatever the case, it is certain that in order to fulfil the ULS criteria, several slab ribs need to be retrofitted for flexural and shear strengthening.

\subsection{The post-tensioning system model}

The inconveniences caused by the necessity for supplementary interventions beside over-concreting led to other retrofitting solutions to be considered. One of the most appealing implies the use of exterior posttensioning. If the slabs can be subjected to counterdeflections through post-tensioning while verifying the SLS conditions, then no other major interventions to the existing structure may be necessary.

Following the previous considerations, it was necessary that the exterior post-tensioning tendon profile and the minimum tensioning force to be found. It was concluded that the post-tensioning is necessary to be placed only below the slab regions having the larger spans (i.e. between and, at the same time, oriented parallel with axes B-C and D-E). The vertical component of the tensioning force causing the lifting of the slab (i.e. generating the vertical counter-deflection) depends upon both the tendon's eccentric position to the existing slab and the magnitude of the tensioning force.

The maximum distance of the tendon to the bottom of the slab was set to $250 \mathrm{~mm}$ at the middle, and to $200 \mathrm{~mm}$ at the quarter distance on both sides of the $12 \mathrm{~m}$ bay. These values were established due to some architectural limitations regarding the clear floor height (i.e. the builder agreed a maximum $300 \mathrm{~mm}$ ceiling drop to permit a proper protection against fire and humidity, while separating walls were additionally provided bellow the areas where tendons require maximum eccentricities).

The stabilized post-tensioning force is also limited to $70 \%$ of the yield force of the tendons (i.e. calculated after all the post-tensioning losses have been consumed). If using tendons with a cross-sectional area of $150 \mathrm{~mm}^{2}$ and a characteristic tensile strength of $1770 \mathrm{MPa}$, the final stress caused by post-tensioning is:

$$
\sigma_{p}=0.7 \times f_{\mathrm{p} 0,1 \mathrm{k}} \cong 1075 M P a
$$

where $\sigma_{p}-$ the final post-tensioning stress; $f_{\mathrm{p} 0,1 \mathrm{k}}-$ the characteristic $0.1 \%$ proof-stress of post-tensioning steel.

The exterior post-tensioning effect is modelled by using frame elements as tendons. The deflecting devices are also modelled with frame elements. Even if there are studies presenting different modelling techniques for the post-tensioning [9], the following simplifications were considered:

- each tendon is divided between the deflection devices into four individual frames;

- the frames between the deflection devices have the bending stiffness released at both ends and the torsional stiffness released at only one end (see Fig. 
10), thus simulating a cable-type behaviour while avoiding unpredictable mechanisms or instabilities;

- the post-tensioning force is induced as a thermal load by applying a minus temperature change, and thus producing an axial contraction of the tendons.

A numerical model example having the frames and the deflecting devices positioned bellow the slabs is presented in Fig. 10.

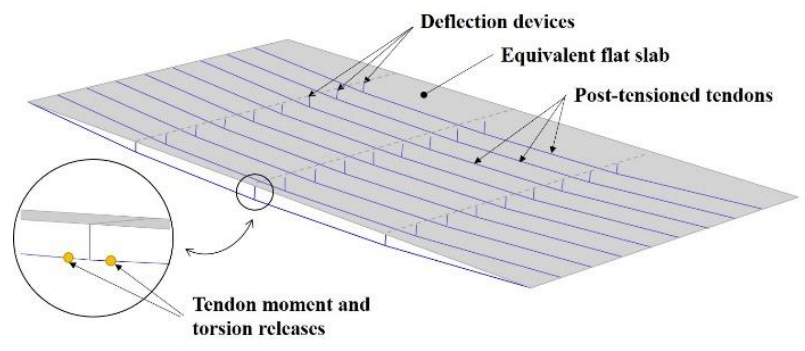

Fig. 10. Exterior post-tensioned slab numerical model.

It should be mentioned that the cable-type behaviour is obtained even if the shear stiffness of the frames is maintained. In the presence of the shear stiffness and the mentioned end releases, a truss-type behaviour is generated instead. However, by neglecting the friction between tendons and deflecting devices, and due to the symmetry of the applied loading (i.e. the temperature load produces equal axial retractions of both ends of the frame), only tension forces (i.e. axial with no compression) are developed. The necessary temperature change is found by the following equation:

$$
\Delta t=\frac{\sigma_{p}}{\alpha_{t} E}
$$

where $\Delta t-$ is the imposed temperature change; $\alpha-$ is the coefficient of thermal expansion, and $E$ - is the modulus of elasticity of the tendon material. Having the final posttensioning stress set to $1075 \mathrm{MPa}$, and taking $E=195000$ $\mathrm{MPa}$ and $\alpha_{t}=0,00001171 /{ }^{\circ} \mathrm{C}$ (i.e. ${ }^{\circ} \mathrm{C}$ - Celsius degrees), the resulted temperature change is $470^{\circ} \mathrm{C}$.

The deflection devices were determined with respect to the estimated forces induced by post-tensioning: the vertical component causing the lifting of the slab, and the horizontal component coming from the friction with the tendons. Therefore, the deflection devices are designed as steel frames subjected to axial, bending and shear forces. Coated and grouted strands are proposed in order to minimize these frictions, but also to reduce the risk of corrosion. Based on these considerations, the design suggested the use of square hollow cross-section steel bars as deflection devices, having: the cross-sectional dimensions of $80 \times 80 \times 5 \mathrm{~mm}$ (i.e. $80 \mathrm{~mm}$ total depth and width, and $5 \mathrm{~mm}$ thickness), and the steel yield strength of $275 \mathrm{MPa}$.

The analysis of the post-tensioning applied in the lack of any other vertical load (i.e. also excluding the selfweight of the existing slabs) generated the deflected shapes presented in Fig. 11, Fig. 12 and Fig. 13. It should be observed that slab counter-deflections are present to all floors. This confirms the efficiency of the proposed modelling technique to include the exterior posttensioning effect. The self-weight of the slabs is excluded from this particular analysis merely to emphasise the uplifting effect, and it doesn't correspond to a realistic loading situation by its own.

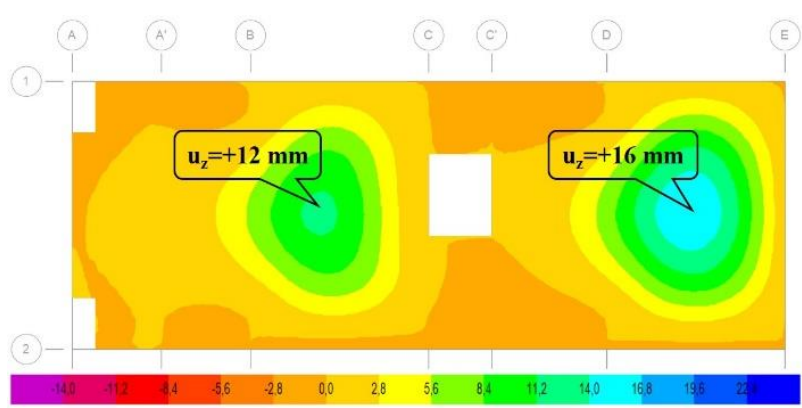

Fig. 11. Pure post-tensioned slab deformed shape - basement floor.

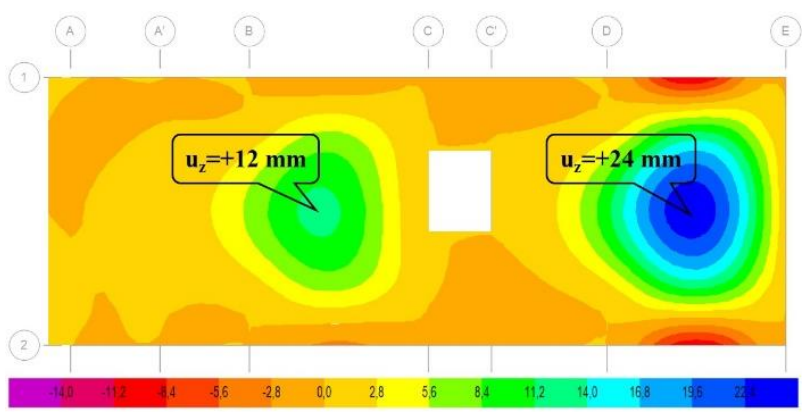

Fig. 12. Pure post-tensioned slab deformed shape - semibasement floor.

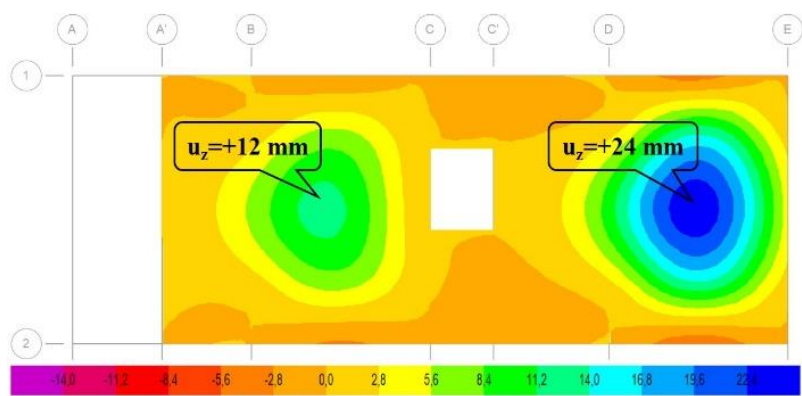

Fig. 13. Pure post-tensioned slab deformed shape - ground floor.

If the vertical loads are added (i.e. including the selfweight of the slabs), then the deflected shapes presented in Fig. 14, Fig. 15 and Fig. 16 are obtained. The permanent and live load values were taken as in the previous analyses. The shown relative vertical displacements of the slabs are lower or at least equal with the maximum allowed, thus indicating the exterior posttensioning as a viable retrofitting solution.

Moreover, the verifications performed at the ULS suggest that no supplementary structural interventions are needed beside those involving the installation of the posttensioning system (i.e. components of the deflection and anchorage devices). 


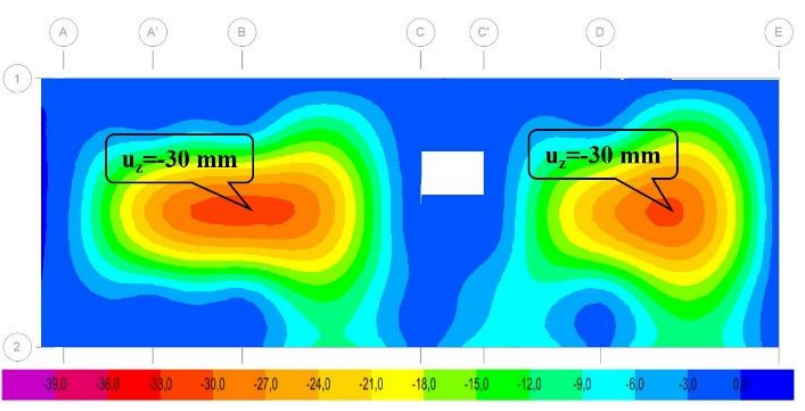

Fig. 14. Post-tensioned slab deformed shape - basement floor.

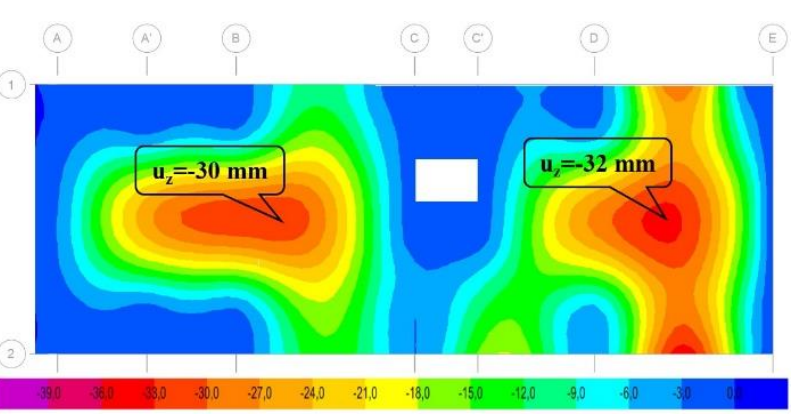

Fig. 15. Post-tensioned slab deformed shape - semi-basement floor.

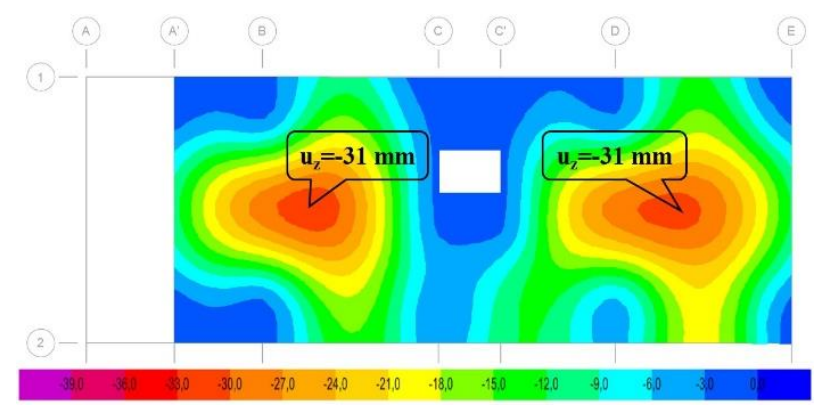

Fig. 16. Post-tensioned slab deformed shape - ground floor.

\subsection{Comparison of the analytical results}

If both retrofitting solutions are compared in terms of slab deflections, it is clear that the highest stiffness is obtained for the top concrete layer solution. The deflections obtained from the in-situ initial state model $\left(u_{z, I N}\right)$, the top concrete layer model $\left(u_{\mathrm{z}, \mathrm{CL}}\right)$, and the post-tensioning model $\left(u_{z, \mathrm{PT}}\right)$ are presented in Table 2 . The values are reported to the admissible SLS deflections ( $\left.u_{\mathrm{z}, \mathrm{ADM}}\right)$, also. Only the slab deflections that are measured between axes B-C and D-E are reported.

The highest deflections are obtained for the semibasement top slab, between axes D-E. Even if the concrete strength is lower at the ground floor top slab, the live loads at the semi-basement floor are higher (i.e. office area destination) and this causes higher deflections. More tendons will be needed in these areas to compensate the slab deflections, as it will be seen in the following.
Table 2. Numerical analyses results comparison.

\begin{tabular}{|c|c|c|c|c|c|c|}
\hline \multirow[t]{2}{*}{ Slab } & \multicolumn{2}{|c|}{$\begin{array}{c}\text { Initial state } \\
\text { deflection } \\
u_{\mathrm{z}, \mathrm{IN}}[\mathrm{mm}] \\
\left(u_{\mathrm{z}, \mathrm{IN}} / u_{\mathrm{z}, \mathrm{ADM}}\right)\end{array}$} & \multicolumn{2}{|c|}{$\begin{array}{c}\text { Top concrete } \\
\text { layer deflection } \\
u_{\mathrm{z}, \mathrm{CL}}[\mathrm{mm}] \\
\left(u_{\mathrm{z}, \mathrm{CL}} / u_{\mathrm{z}, \mathrm{ADM}}\right)\end{array}$} & \multicolumn{2}{|c|}{$\begin{array}{c}\text { Exterior post- } \\
\text { tensioning } \\
\text { deflection } \\
u_{\mathrm{z}, \mathrm{PT}}[\mathrm{mm}] \\
\left(u_{\mathrm{z}, \mathrm{PT}} / u_{\mathrm{z}, \mathrm{ADM}}\right)\end{array}$} \\
\hline & B-C & D-E & B-C & D-E & B-C & D-E \\
\hline $\begin{array}{l}\text { Basement } \\
\text { Top Slab }\end{array}$ & $\begin{array}{c}-43 \\
(1.34)\end{array}$ & $\begin{array}{c}-50 \\
(1.56)\end{array}$ & $\begin{array}{c}-16 \\
(0.5)\end{array}$ & $\begin{array}{c}-20 \\
(0.63)\end{array}$ & $\begin{array}{c}-30 \\
(0.94)\end{array}$ & $\begin{array}{c}-30 \\
(0.94)\end{array}$ \\
\hline $\begin{array}{c}\text { Semi- } \\
\text { basement } \\
\text { Top Slab }\end{array}$ & $\begin{array}{c}-45 \\
(1.41)\end{array}$ & $\begin{array}{c}-62 \\
(1.94)\end{array}$ & $\begin{array}{c}-18 \\
(0.56)\end{array}$ & $\begin{array}{c}-23 \\
(0.72)\end{array}$ & $\begin{array}{c}-30 \\
(0.94)\end{array}$ & $\begin{array}{c}-32 \\
(1.00)\end{array}$ \\
\hline $\begin{array}{l}\text { Ground } \\
\text { Floor Top } \\
\text { Slab }\end{array}$ & $\begin{array}{c}-45 \\
(1.41)\end{array}$ & $\begin{array}{c}-59 \\
(1.84)\end{array}$ & $\begin{array}{c}-18 \\
(0.56)\end{array}$ & $\begin{array}{c}-23 \\
(0.72)\end{array}$ & $\begin{array}{c}-31 \\
(0.97)\end{array}$ & $\begin{array}{c}-31 \\
(0.97)\end{array}$ \\
\hline
\end{tabular}

It should be mentioned that neither analysis showed the necessity to retrofit the perimeter beams. This is because there is enough reinforcement provided in order to overtake the exterior forces (i.e. counting separately on the supplementary weight of the top concrete layer or the vertical component of the post-tensioning force). The flexural and the shear capacity of these beams were estimated with the help of the Section Designer module (i.e. sectional analysis software integrated in SAP2000 [5]) and the recommendations of Eurocode 2 [3], respectively. In the regions were post-tensioning should be provided, the perimeter beams have $300 \times 600 \mathrm{~mm}$ the cross-sectional dimensions. Four rebars of $25 \mathrm{~mm}$ in diameter are placed at both the upper and the bottom sides of the beams and through the whole length. Vertical stirrups spaced at $150 \mathrm{~mm}$ of $8 \mathrm{~mm}$ in diameter are also provided through the whole length of the beams. Under the mentioned material strengths (i.e. C8/10 concrete class and reinforcement having the yield strength of 345 $\mathrm{kPa}$ and the tensile strength of $510 \mathrm{kPa}$ ), the following bending and shear capacities are obtained:

- Bending yield moment $=335 \mathrm{kNm}$;

- Bending ultimate moment $=407 \mathrm{kNm}$;

- Design shear resistance without shear reinforcement $=57 \mathrm{kN}$;

- Design shear resistance provided by the transversal reinforcement for a concrete strut angle of 45 degrees $=75 \mathrm{kN}$;

- Design shear resistance limited by crushing of the compression struts $=233 \mathrm{kN}$.

The maximum bending moment obtained from the analyses is lower than $200 \mathrm{kNm}$, while the maximum external shear force does not exceed $70 \mathrm{kN}$.

\section{Retrofitting solutions}

The analyses performed for the ULS offer the stress distribution to be used in design for both the considered retrofitting solution. As mentioned before, the top concrete layer solution implies additional reinforcement for the new concrete and at the interface of the two concretes, while if exterior post-tensioning is used, then 
supplementary devices will have to be designed and mounted as deflection devices and end anchorages.

\subsection{The top concrete layer retrofitting solution}

The new concrete layer should be cast above all the existing slabs, and not just over the areas where the deflections do not meet the SLS requirements. The decision came following the intention to ensure a rigid support for all the coming floor layers.

Eurocode 2 [3] standard specifies that the shear at the interface between concretes cast at different times should be taken by the reinforcement crossing the interface. The reinforcement is calculated based on the shear force distribution. The equation upon which the reinforcement at the interface is calculated, is given bellow:

$$
\begin{gathered}
\frac{\beta \cdot V_{E d}}{z \cdot b_{i}}= \\
\underbrace{c \cdot f_{c t d}+\mu \cdot \sigma_{n}+\rho \cdot f_{y d}(\mu \cdot \sin \alpha+\cos \alpha)}_{v_{E d i}} \\
\leq 0.5 \cdot v \cdot f_{c d}
\end{gathered}
$$

where: $v_{E d i}-$ is the design value of the shear stress in the interface; $v_{R d i}$ - is the design shear resistance at the interface; $\beta$ - is the ratio of the longitudinal force in the new concrete area and the total longitudinal force either in the compression or tension zone, both calculated for the section considered; $V_{E d}-$ is the transverse shear force; $z-$ is the lever arm of composite section; $b_{i}$ - is the width of the interface; $c$ and $\mu$-are factors which depend on the roughness of the interface; $f_{\text {ctd }}-$ is the design tensile strength of the concrete; $f_{y d}$ and $f_{c d}$ - are the design yield strength of reinforcement and the design value of concrete compressive strength, respectively; $\rho$ - is the ratio of the reinforcement crossing the interface and the area of the interface or joint; $v$ - is a strength reduction factor (see Eurocode 2 [3]); and $\alpha-$ is the angle of the interface reinforcement.

The distribution of the reinforcement crossing the interface is obtained based on the shear force diagrams. A proper anchorage length is provided in both concretes (i.e. the existing concrete and the new top concrete layer), thus increasing steel reinforcement quantities. A detail of the interface reinforcement is shown in Fig. 17. The total steel quantity crossing the interface for all the slabs is estimated to approximately $1500 \mathrm{~kg}$.

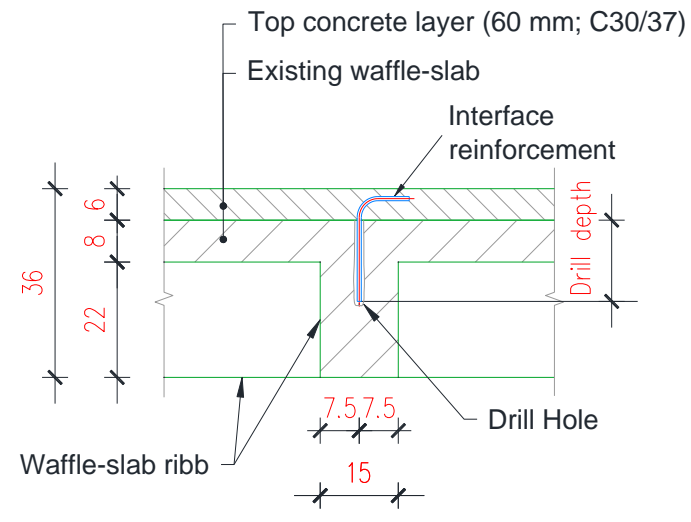

Fig. 17. Interface reinforcement detail.

The longitudinal reinforcement in the new concrete layer is found thanks to the bending moment diagrams resulting from the ULS analysis. The obtained longitudinal reinforcement ratio for the top concrete layer is approximately 0.005 , thus meaning approximately 9200 $\mathrm{kg}$ of steel reinforcement for all the retrofitted slabs.

Based on the same ULS analysis it was found that supplementary punching shear reinforcement is necessary near the piers supporting the slabs. This is a consequence of having a low strength concrete and a supplementary dead load coming from the additional concrete layer. Steel anchor rods were used as punching shear reinforcement. These anchor rods were designed to be mounted into drilled holes crossing the whole existing slab and fixed with injection mortar or a resin-based grout. Bolts and special designed steel plates are use as anchorage devices, and a detail of this retrofitting solution is shown in Fig. 18. The slab in these areas near the piers is flat (i.e. no ribs are provided) and has a thickness of $300 \mathrm{~mm}$ without over-concreting. The total steel quantity for the punching shear retrofitting solution for all the slabs is estimated to approximately $1400 \mathrm{~kg}$.

Another consequence of having a diminished concrete strength is the reduction of the shear resistance, especially of the capacity limited by crushing of the compression struts (i.e. named $V_{\mathrm{Rd}, \max }$ in Eurocode 2 [3]). Here, the capacity is directly related to the design value of concrete compressive strength and the width of the concrete element. Therefore, the ULS analysis showed that the induced shear forces can no longer be overcome by some of the slab ribs.

The proposed retrofitting solution for these elements consists in fixing a $U$ channel steel profile above the slab ribs and combined with exterior stirrups. 


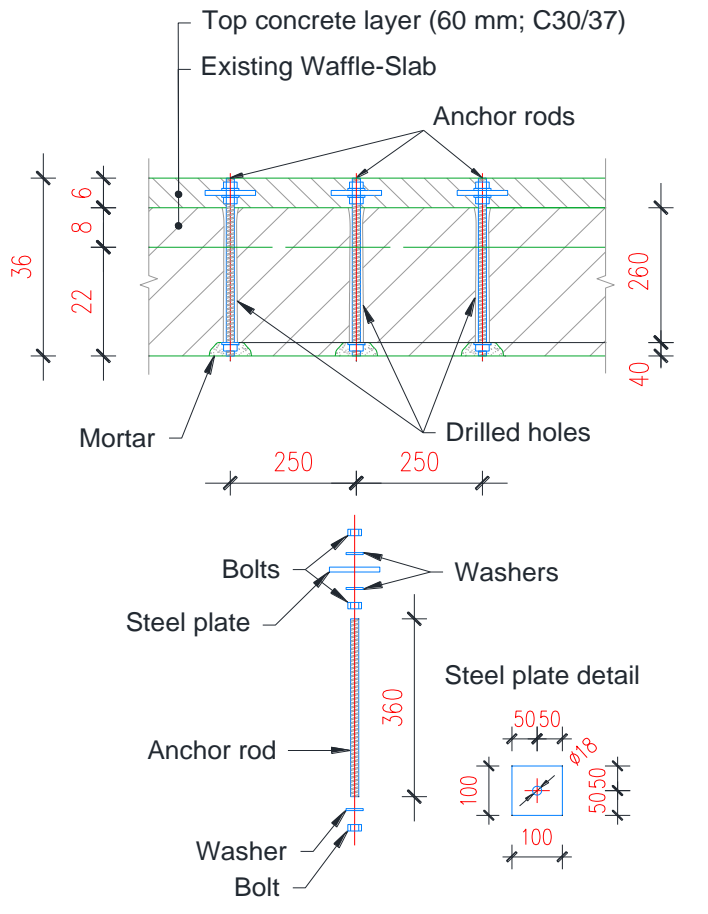

Fig. 18. Punching shear retrofitting solution.

A steel plate is placed under the steel profile to protect the existing concrete. Steel angles with $\mathrm{L}$ profiles are provided at the corners of the slab ribs for the same protective reason. All steel elements are welded. For simplicity, all the shear force is considered to be taken by the steel profile and, therefore, it is designed accordingly. A detail of this retrofitting solution is presented in Fig. 19. The total steel quantity for all the slabs, including the steel profiles, is estimated to approximately $2200 \mathrm{~kg}$. A total of 39 slab ribs require interventions of this kind.
Finally, a total steel quantity of $14300 \mathrm{~kg}$ is estimated to be needed for this retrofitting solution and a total concrete volume of 70 cubic meters (i.e. the volume of the new concrete layer).

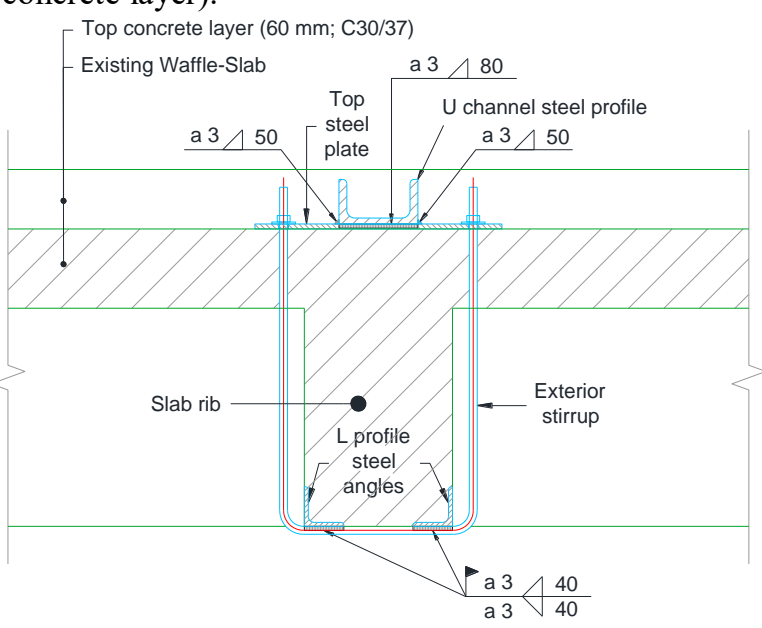

Fig. 19. Punching shear retrofitting solution.

\subsection{The post-tensioning retrofitting solution}

Despite all the appearances, the proposed retrofitting solution using exterior post-tensioning is actually much simpler. All the tendons were placed under the existing slabs and anchored into the exterior concrete beams. The tendon layout is ensured with steel deflection devices that are designed for a maximum of $1 \mathrm{~m}$ radius of the strands. Moreover, the ULS analysis showed no risk in having exterior forces that are higher than the structural elements are capable to overcome. A representation of the tendon layout is shown in Fig. 20.

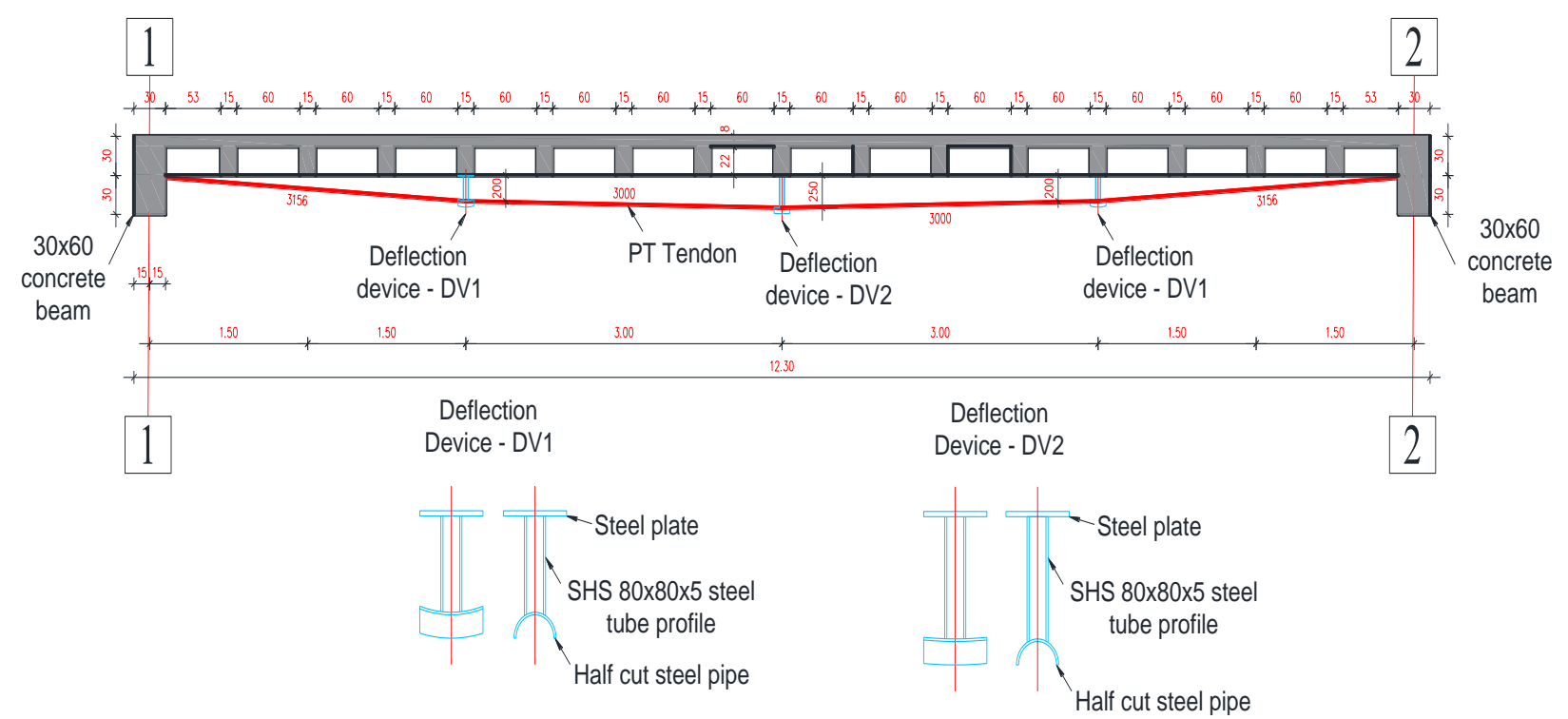

Fig. 20. Exterior tendon profile.

The tendons are designed to be placed under the slab ribs and spaced at $0.75 \mathrm{~m}$ (i.e. also the distance between the ribs). The number of tendons gets higher in the areas where the maximum deflections were obtained during the analysis. These areas are located at the semi-basement and at the ground floor, and between axes D and E. A plan representation of the tendons for each floor is offered in Fig. 21, Fig. 22 and Fig. 23. As seen, a total of 62 tendons are needed, each having the length of approximately $12.350 \mathrm{~m}$. 


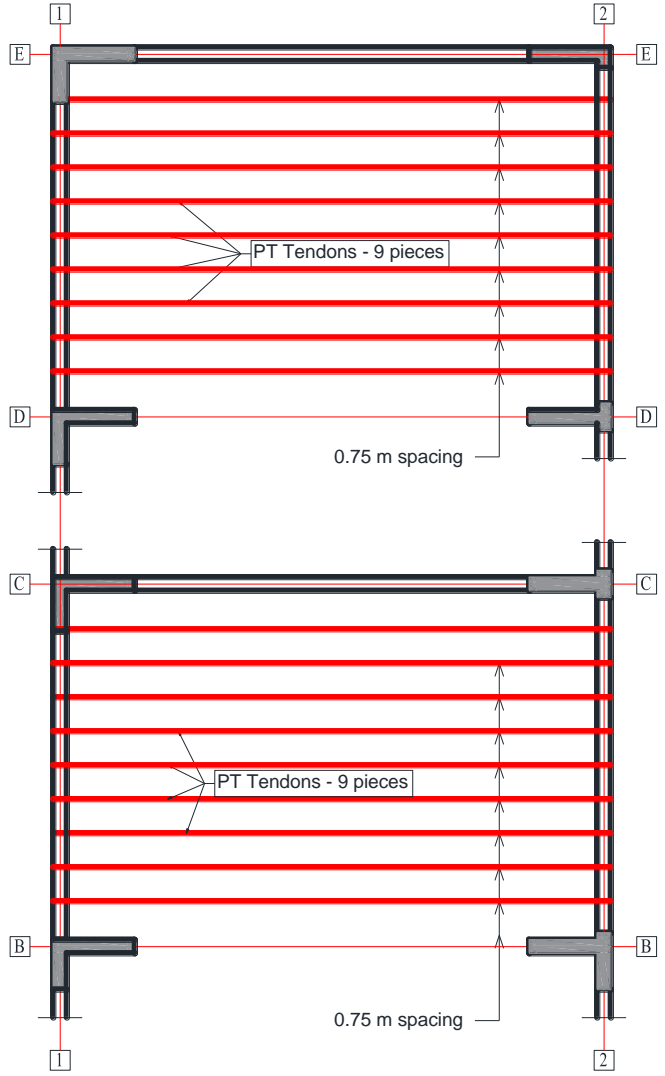

Fig. 21. Positioning of tendons - basement floor.

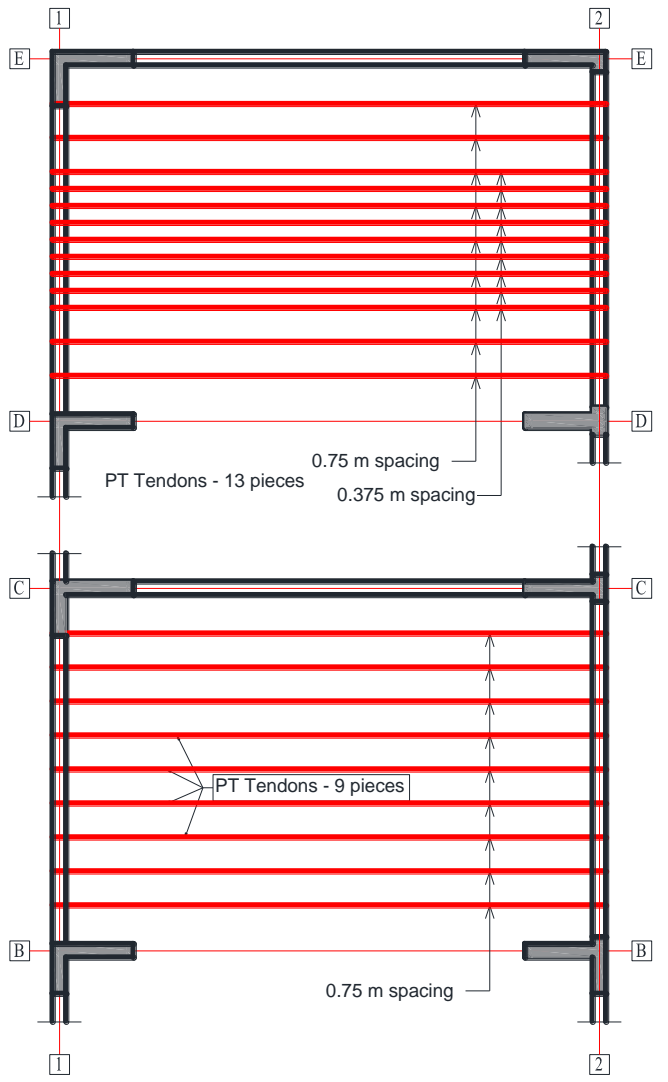

Fig. 22. Positioning of tendons - ground floor.

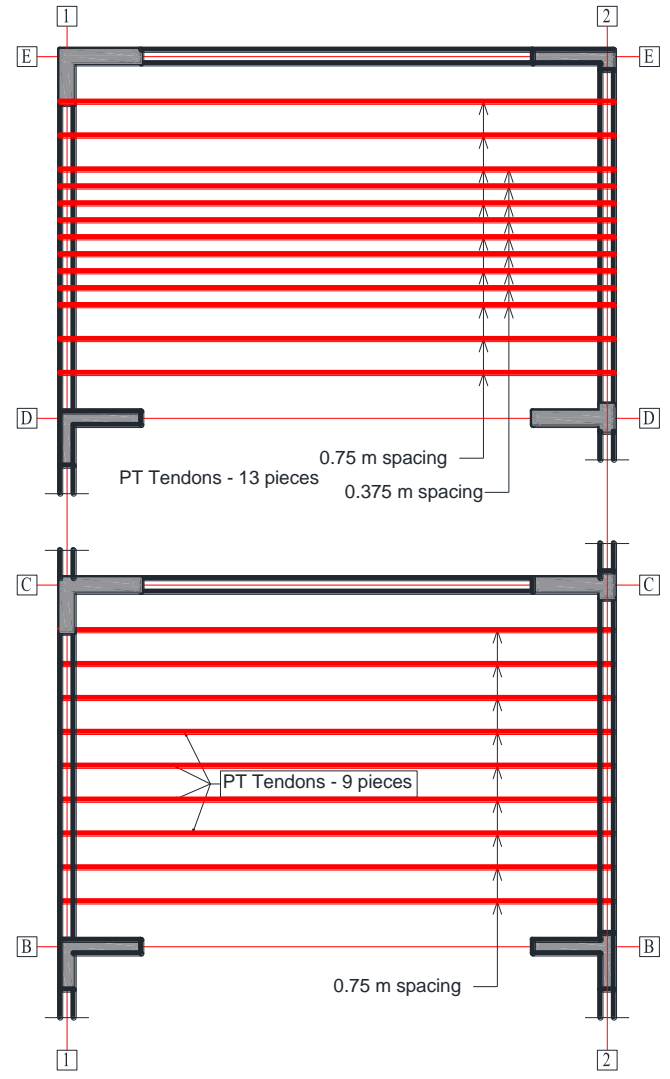

Fig. 23.Positioning of tendons - semi-basement floor.

A total of 124 pieces of deflecting devices DV1 and 62 pieces of deflecting devices DV2 are needed. The total steel consumption that is estimated for this retrofitting solution is estimated at about $1100 \mathrm{~kg}$. Of course, no additional concrete layer is needed and only the areas where the maximum deflections were encountered must be retrofitted.

Due to the high-tension forces in the tendons and the low concrete class of the perimeter beams, supplementary anchor devices are needed at both ends. These devices are meant to reduce the tensions induced in the support elements caused by the post-tensioning, and therefore should be made from thick steel plates. The dimensions are established based on the tension forces from the strands. The resulted quantities were contained in the estimated consumptions presented previously.

\subsection{Comparison of the proposed retrofitting solutions}

Except for the simplicity of the solution, it is of great importance to compare the overall steel consumptions of the two retrofitting solutions. It should be mentioned that these quantities are estimations, but no significant differences are expected to be encountered in practice.

Therefore, the steel consumption for the top concrete layer solution is 13 times higher than post-tensioning solution. A cost estimation is considered not so relevant, merely because it is difficult to estimate the final impact upon sales while dealing with a smaller living space due to post-tensioning. Based on the major difference regarding the steel consumption and by the fact that no 
additional concrete layer and no supplementary structural interventions are needed for the post-tensioning solution, is assumed that this last-mentioned retrofitting solution is also the costliest efficient.

\section{Conclusions}

Two retrofitting solutions were studied for a multi-storey building having waffle-slab floors. The necessity to retrofit the slabs came as a consequence of detecting poor concrete strengths in the already cast elements. The SLS analysis showed that the maximum allowed deflections are highly exceeded, while the SLU analysis did not suggested any necessary structural interventions when analysing the in-site situation. Therefore, the retrofitting solutions were adopted and focused merely on the stiffness enhancement of the slabs to long period loadings.

The top concrete layer solution was considered simpler at first, but complex structural interventions have been suggested after performing the SLU analysis. The necessary thickness of the top concrete layer is $60 \mathrm{~mm}$, and the analysis showed that the infrastructure has the capacity to overcome the resulting additional weight.

The exterior post-tensioning solution is considered to be the most efficient. The overall steel consumption is 13 times lower than obtained by over-concreting. If the intension is increasing the stiffness, then it is considered that the presented post-tensioning solution is even more cost-efficient than using carbon fibre. Therefore, exterior post-tensioning should be used as an efficient retrofitting solution to overcome the SLS excessive deflections.

\section{References}

1. Normativ privind evaluarea in-situ a rezistenţei betonului din constructiile existente, indicativ NP 137, (2014).

2. BS EN 13791: 2007: Assessment of in-situ compressive strength in structures and pre-cast concrete components.

3. EN 1992- 1- 1: 2004: Eurocode 2: Design of concrete structures - Part 1- 1: General rules and rules for buildings. Incl.

4. Computers and Structures Inc., ETABS - Extended Three Dimensional Analysis of Building Systems Nonlinear v16.0.0., California, USA, (2016).

5. Computers \& Structures Inc., CSI Analysis Reference Manual For SAP2000®, ETABS®, and SAFE, (2016)

6. S. Timoshenko and S. Woinowsky-Krieger, Theory of Plates and Shells, 2nd ed, McGraw-Hill, N.Y. USA, (1987).

7. I. Chowdhury and J. P. Singh, Analysis and design of waffle slabs with different boundary conditions, Indian Concr. J., vol. 86, no. 6, pp. 43-52, (2012).

8. W. Kanok-Nukulchai and A. K. Gilani, A macroelement for waffle slab analysis, Comput. Struct., vol. 15, no. 2, pp. 117-122, (1982).

9. A. Faur, C. Mircea, and M. Păstrav, A Modeling Technique for Precast Concrete Frames with Hybrid
Connections, Acta Technica Napocensis: Civil Engineering \& Architecture, vol. 55, no. 3, 2012. 